\title{
Young Peoples' Perspectives on the Role of Harm Reduction Techniques in the Management of Their Self-Harm: A Qualitative Study
}

\author{
Davies $\mathrm{J}^{\mathrm{a}^{*}}$, Pitman $\mathrm{A}^{\mathrm{a}}$, Bamber $\mathrm{V}^{\mathrm{a}}$, Billings $\mathrm{J}^{\mathrm{a}}$, Rowe $\mathrm{S}^{\mathrm{a}}$ \\ ${ }^{a}$ UCL Division of Psychiatry, University College London, London, UK \\ *Corresponding author: Jessica.davies.18@alumni.ucl.ac.uk
}

Jessica Davies is a graduate of the MSc Clinical Mental Health Sciences at University College London. She has previous clinical experiences working with children and high-risk adolescents in community settings and within the NHS. Her research interests include self-harm, suicidality, mental health and education, and child and adolescent mental health.

Dr Alexandra Pitman is a Clinical Associate Professor in the University College London Division of Psychiatry and an Honorary Consultant Psychiatrist at Camden and Islington NHS Foundation Trust. She is interested in understanding risk factors for suicide attempt and in developing interventions to address them.

Victoria Bamber is a graduate of the MSc Clinical Mental Health Sciences at University College London. She has previous clinical experiences working with high-risk adolescents within NHS settings.

Dr Joanne Billings is a Clinical Associate Professor in the Division of Psychiatry. Her clinical and research interests include complex trauma, vicarious trauma, trauma and psychosis, early intervention, mental health wellbeing and resilience, and qualitative methodology.

Dr Sarah Rowe is an Associate Professor at University College London Division of Psychiatry and Deputy Director of the MSc in Mental Health Sciences programme. Her research interests include harm-minimisation for self-harm, child and adolescent mental health, personality and eating disorders. 


\section{Young Peoples' Perspectives on the Role of Harm Reduction Techniques in the Management of Their Self-Harm: A Qualitative Study}

Objective: Self-harm is a common phenomenon amongst young people, often used to regulate emotional distress. Over the last decade harm reduction approaches to selfharm have been introduced as a means to minimize risk and reinforce alternative coping strategies. However, there is a stark absence of research into the perceived usefulness of such techniques amongst adolescents, and previous studies have highlighted ethical concerns about advocating 'safer' forms of self-harm. This study aimed to investigate the perceived usefulness of harm reduction techniques for adolescents who self-harm.

Method: We purposively recruited current clients of a British early intervention program supporting young people in managing self-harm. We conducted semistructured interviews and analyzed transcripts using thematic analysis.

Results: Eleven interviews with service users aged 14 to 15 years identified three main themes: (1) Controlling the uncontrollable; (2) Barriers to practising safer self-harm; and (3) Developing a broad repertoire of harm reduction techniques. Participants expressed mixed views regarding the usefulness of such approaches. Some described greater competence and empowerment in self-harm management, whilst others described the utility of harm reduction methods as either short-lived or situationspecific, with the potential for misuse of anatomical knowledge to cause further harm to high-risk adolescents.

Conclusion: The findings from our sample suggest harm reduction techniques have a place in self-harm management for some individuals, but their usage should be monitored and offered alongside alternative strategies and therapeutic support. Our study highlights the need for further research on who would benefit from these techniques and how they can be implemented successfully. 
Keywords: self-harm, self-injury, harm reduction, harm minimization, young people

\section{Highlights}

(1) Harm reduction can help people who self-harm manage distress and maintain autonomy

(2) People who self-harm have a broad repertoire of harm reduction techniques

(3) Harm reduction can help reduce long-term damage and frequency of self-harm 


\section{Introduction}

Self-harm refers to any non-fatal act performed with the intention of causing harm to oneself (Owens, Hansford, Sharkey, \& Ford, 2016), including self-injury (cutting, self-battery) or self-poisoning (overdose, ingestion of toxic substances) (Hawton, Saunders, \& O’Connor, 2012). Self-harm is relatively common in adolescence, practiced by approximately one in five to one in ten young people (Doyle, Treacy, \& Sheridan, 2015). Despite the perceived benefits of relieving emotional distress (Townsend, 2014), self-harm carries risks of scarring, tendon damage, and serious blood loss (Gurung, 2018), and is a risk factor for psychosocial problems (Borschmann et al., 2017), repeat self-harm (Cully, 2019), accidental death (Hawton, Harriss, \& Zahl, 2006) and suicide (Hawton et al., 2015a). It is therefore important to understand how adolescents manage their self-harm in ways that reduce such risks.

Harm reduction approaches for self-harm were developed following service user requests for autonomy and self-management (Gonzales \& Bergstrom, 2013). Primarily focused on self-injury, techniques aim to lessen long-term damage and self-harm frequency; including engaging in less physically damaging behaviors such as pinging elastic bands against the skin, providing anatomical information to reduce tissue damage, or providing first aid kits for wound-care (Pengelly, Ford, Blenkiron, \& Reilly, 2008). This approach recognizes self-harm as a means of coping with distress (Madge et al., 2011) whilst rejecting traditional preventative strategies thought to introduce unrealistic expectations (Kelly, Jorm, Kitchener, \& Langlands, 2008; Inckle, 2011) and behavioral escalation (Holley, Horton, Cartmail, \& Bradley, 2012). However, there are ethical concerns about advocating 'safer' forms of self-harm, including concerns amongst professionals that failing to prevent injury might constitute a breach of duty of care (Sullivan, 2017) and encourage self-harm whilst neglecting underlying psychological causes (Sullivan, 2019). Also, whilst some clinicians feel comfortable advising on wound-care, they are less willing to provide anatomical 
information or sterile razors (Hosie \& Dickens, 2018), due to the potential to escalate risk of harm (James, Samuels, Moran, \& Stewart, 2017). Conversely, these approaches may be justified if it reduces the damage associated with self-harm (Sullivan, 2017).

There is a lack of research investigating the effectiveness and acceptability of harmreduction approaches for self-harm. The limited number of studies include a retrospective analysis of adolescent in-patient experiences (Livesey, 2009), and a six-year audit report across three female forensic in-patient units examining the prevalence of self-harm before and after implementation of a harm reduction program (Birch, Cole, Hunt, Edwards, \& Reaney, 2011). Whilst these studies were conducted within clinical settings and involved small participant samples, they establish promising applications of the harm reduction paradigm in supporting those who self-harm. Conversely, Wadman et al. (2019)'s mixed methods analysis of adolescent perspectives on harm reduction reported low acceptability of such approaches. Although this work included community samples, it explored young people's views on a narrower range of harm reduction techniques, which included squeezing ice cubes, but not on anatomical information or damage limitation techniques.

Considering these concerns, and the general lack of research on this topic, we aimed to conduct qualitative interviews to explore young people's perspectives on harm reduction techniques in managing their self-harm.

\section{Method}

\section{Study design}

This study formed part of a wider project investigating perceptions of harm reduction among adolescents who self-harm, their parents, and practitioners. To address our aim, we followed an interpretivist epistemological approach (Aliyu, Singhry, Adamu, \& Abubakar, 2015), using face-to-face semi-structured interviews to investigate adolescents' views of harm reduction techniques in managing their self-harm. 


\section{Participants}

We purposively recruited current clients of Mind and Body (MAB); an early intervention program supporting young people (aged 13-17 years) who engage in or may be vulnerable to self-harming behaviours. The MAB program is facilitated through Addaction; one of the UK's leading substance misuse and mental health treatment charities. The charity supports individuals who do not meet the threshold for Child and Adolescent Mental Health Services but could benefit from specialised input. Its programmes advocate harm reduction techniques and encourage young people to create their own strategies to manage self-harm. MAB offers support throughout the English county of Kent through school-based programs or within the community, comprising of eight group sessions accompanied by three one-to-one sessions with a practitioner for needs-based support. Our inclusion criteria were attendees who were either currently self-harming or reported a history of self-harm.

\section{Reflexivity}

Interviews were conducted by the lead author (JD), who has lived experience of self-harm and an interest in its clinical management. Her personal stance on harm reduction supported its usage in managing self-harm. Due to JD's lived experience, she attended regular supervision with a clinical academic throughout the process of data collection and analysis and ensured clear access to clinical resources in the event that risk issues arose during the course of the study. Other members of the research team were a Research Psychiatrist (AP), Research Psychologist (SR), MSc student (VB), and a Consultant Clinical Psychologist and qualitative mental health researcher (JB). Their views were broadly positive towards harm reduction as potentially offering advantages to people who self-harm. JD had no previous contact with interviewees before the study.

\section{Materials}

Topic guide 
As adolescent perspectives of harm reduction are currently under-researched, the study's topic guide (see supplemental Appendix A) was influenced by policy literature (NICE, 2011), published research involving staff views (Hosie \& Dickens, 2018), limited harm reduction literature (Inckle, 2011; Peters et al., in preparation), and suggestions from an advisory group of three previous MAB clients. The drafted guide was further refined in a focus group comprised of six mental health researchers, led by SR. An adolescent volunteer with a history of self-harm was recruited for a pilot interview to assess the topic guide's acceptability (Polit \& Beck, 2006). We sought advice through social media regarding how best to approach this sensitive topic and optimize information disclosure whilst protecting participants' wellbeing.

\section{Procedure}

Participants were interviewed towards the end of their involvement with the MAB program. Those receiving community-based support were interviewed in private rooms in youth centers; those enlisted in school-based programs were interviewed in private classrooms at their schools. Interviews lasted between 23 and 53 minutes, and no additional persons were present. An encrypted dictaphone recorded interviews. Fieldnotes and reflective notes were created following interviews to assist transcribing and analysis. Respondents received $£ 15$ vouchers upon completion in acknowledgement of their time. The topic guide was revised iteratively between interviews, but no repeat interviews were conducted. Participants were offered the option of receiving a copy of their transcript to comment on.

Ethical approval was granted by the UCL Research Ethics Committee (ID: $15303 / 001)$.

\section{Data Analysis}

Interviews were audio-recorded and transcribed verbatim by JD. Participants' names were pseudonymized to mask identity. We used thematic analysis (Braun \& Clarke, 2006) with an inductive approach to derive analytic themes from interviewees' experiences. 
Two researchers (JD \& VB) coded the first two transcripts independently. They discussed coding throughout, identifying pre-existing biases and blind spots within initial analysis. The remaining transcripts were coded solely by JD. Emergent themes were checked across transcripts and repeatedly discussed with the team to enhance validity.

\section{Results}

\section{Participant Characteristics}

Forty-one adolescents met inclusion criteria. Seven decided not to participate due to external commitments, and 22 declined without indicating reasons. Twelve interviews were therefore conducted, although one was omitted from analysis due to issues with written parental consent. Consequently, data from 11 interviews were fully analysed and data saturation was reached in this process. Nine participants were sent transcripts, although none suggested edits. Four participants were community clients and seven from secondary schools throughout Kent. Participant characteristics are summarized in Table 1. 
Table 1. Participant characteristics $(\mathrm{n}=11)$.

\begin{tabular}{|c|c|c|c|c|c|c|c|c|}
\hline Pseudonym & $\begin{array}{l}\text { Age at } \\
\text { interview }\end{array}$ & Gender & Ethnicity & $\begin{array}{l}\text { Age at } \\
\text { onset of } \\
\text { self-harm }\end{array}$ & $\begin{array}{l}\text { Current/past } \\
\text { self-harm }\end{array}$ & $\begin{array}{l}\text { Reported } \\
\text { method(s) of } \\
\text { harm }\end{array}$ & $\begin{array}{l}\text { Reported precursors to } \\
\text { self-harm }\end{array}$ & $\begin{array}{l}\text { Reported methods of harm } \\
\text { reduction techniques used }\end{array}$ \\
\hline Beth & 15 & Female & White British & 13.5 & Current & Cutting & $\begin{array}{l}\text { Bereavement, school } \\
\text { stressors }\end{array}$ & $\begin{array}{l}\text { Pinging elastic bands against } \\
\text { skin, squeezing ice cubes, } \\
\text { wound-care }\end{array}$ \\
\hline Cathy & 15 & Female & White Irish & 13 & Past & $\begin{array}{l}\text { Cutting, } \\
\text { digging nails } \\
\text { into skin, } \\
\text { restricting food }\end{array}$ & $\begin{array}{l}\text { Stressful home } \\
\text { environment, friendship } \\
\text { breakdown, lack of } \\
\text { control, school stressors }\end{array}$ & $\begin{array}{l}\text { Pinging elastic bands against } \\
\text { skin, shortening fingernail } \\
\text { length, wound-care to reduce } \\
\text { scarring, sterilizing equipment }\end{array}$ \\
\hline
\end{tabular}




\begin{tabular}{|c|c|c|c|c|c|c|c|c|}
\hline Donna & 15 & Female & White British & 13 & Current & $\begin{array}{l}\text { Cutting, } \\
\text { digging nails } \\
\text { into skin }\end{array}$ & $\begin{array}{l}\text { Lack of control, school } \\
\text { stressors, friendship } \\
\text { breakdown }\end{array}$ & $\begin{array}{l}\text { Pinging elastic bands against } \\
\text { skin, eating spicy food, } \\
\text { punching pillows, sterilizing } \\
\text { equipment, wound-care, } \\
\text { pinching skin as an alternative to } \\
\text { cutting }\end{array}$ \\
\hline Elsa & 15 & Female & White British & 15 & Current & $\begin{array}{l}\text { Cutting, hitting } \\
\text { hard surfaces }\end{array}$ & $\begin{array}{l}\text { Frustrations, boredom, } \\
\text { guilt }\end{array}$ & Wound-care \\
\hline Freya & 15 & Female & $\begin{array}{l}\text { White/Eastern } \\
\text { European mixed }\end{array}$ & 11 & Past & $\begin{array}{l}\text { Cutting, } \\
\text { burning, } \\
\text { picking skin }\end{array}$ & $\begin{array}{l}\text { Life events concerning } \\
\text { family }\end{array}$ & $\begin{array}{l}\text { Running hands under cold water, } \\
\text { wound-care, sterilizing } \\
\text { equipment }\end{array}$ \\
\hline George & 15 & Male & White British & 14 & Past & Cutting & $\begin{array}{l}\text { Bullying, } \\
\text { overwhelming events }\end{array}$ & $\begin{array}{l}\text { Pinging elastic band against } \\
\text { skin, wound-care, sterilizing } \\
\text { equipment }\end{array}$ \\
\hline
\end{tabular}




\begin{tabular}{|c|c|c|c|c|c|c|c|c|}
\hline Harry & 15 & Male & White British & 13 & Past & $\begin{array}{l}\text { Cutting, taking } \\
\text { pills, overdose }\end{array}$ & $\begin{array}{l}\text { Bullying, struggling } \\
\text { with school and home- } \\
\text { life }\end{array}$ & $\begin{array}{l}\text { Hitting punching bags and } \\
\text { pillows, learning anatomical } \\
\text { information, biting tongue as an } \\
\text { alternative to cutting }\end{array}$ \\
\hline Isaac & 15 & Male & White British & 12 & Past & $\begin{array}{l}\text { Cutting, hitting } \\
\text { hard surfaces }\end{array}$ & $\begin{array}{l}\text { Low mood, sensation } \\
\text { seeking }\end{array}$ & $\begin{array}{l}\text { Wound-care, sterilizing } \\
\text { equipment, pinging elastic band } \\
\text { against skin, eating sour sweets, } \\
\text { punching pillows }\end{array}$ \\
\hline Jane & 15 & Female & White British & 14 & Past & $\begin{array}{l}\text { Cutting, } \\
\text { scratching, } \\
\text { self- } \\
\text { deprecation, } \\
\text { hitting hard } \\
\text { surfaces }\end{array}$ & $\begin{array}{l}\text { Bullying, friendship } \\
\text { breakdown, family } \\
\text { conflict, overwhelming } \\
\text { emotions }\end{array}$ & $\begin{array}{l}\text { Pinging elastic band against } \\
\text { skin, wound-care, sterilizing } \\
\text { equipment }\end{array}$ \\
\hline
\end{tabular}




\begin{tabular}{|c|c|c|c|c|c|c|c|c|}
\hline Keith & 15 & Male & White British & 11 & Past & $\begin{array}{l}\text { Cutting, } \\
\text { restricting } \\
\text { food, bingeing, } \\
\text { hitting/kicking } \\
\text { hard surfaces, } \\
\text { head banging, } \\
\text { sleep } \\
\text { deprivation }\end{array}$ & $\begin{array}{l}\text { Nightmares, lack of } \\
\text { control, life event } \\
\text { concerning family }\end{array}$ & $\begin{array}{l}\text { Punching pillows, eating sour } \\
\text { sweets, wound-care }\end{array}$ \\
\hline
\end{tabular}




\section{Themes}

We identified three themes capturing young peoples' perceptions of harm reduction techniques in the management of their self-harm (see Table 2), discussed below using illustrative quotes.

Table 2. Emergent themes and subthemes.

\begin{tabular}{|c|c|}
\hline Theme & Subthemes \\
\hline Theme 1: Controlling the uncontrollable & $\begin{array}{l}\text { 1a: The importance of autonomy } \\
\text { 1b: Doing something to help yourself } \\
\text { 1c: Less harm, same release }\end{array}$ \\
\hline Theme 2: Barriers to practising safer self-harm & $\begin{array}{l}\text { 2a: A double-edged sword } \\
\text { 2b: Short-lived effects } \\
\text { 2c: A lack of motivation } \\
\text { 2d: The strong influence of impulsivity }\end{array}$ \\
\hline $\begin{array}{l}\text { Theme 3: Developing a broad repertoire of harm } \\
\text { reduction techniques }\end{array}$ & \\
\hline
\end{tabular}

Theme 1: Controlling the Uncontrollable.

Many interviewees viewed self-harm as a strategy for coping with adverse life events and affective instability. This theme captured how engaging in harm reduction techniques helped them manage distress whilst regaining a sense of control through allowing them to self-harm in a safer way.

The Importance of Autonomy. This subtheme captures how a harm reduction paradigm provided young people with a sense of mastery over their self-harm. This included helping conceal their self-harm from others, particularly where they feared stigmatization. 
For example, Harry expressed skepticism over disclosing to others; finding solace in harm-reducing information as a way to maintain secrecy of self-harm, whilst exercising a sense of responsibility in caring for himself. He described this in detail, explaining how “...people got a way to not tell people and do it by themselves... people could just think you're bored when you're [pinging elastic bands], but really you're actually doing it to help yourself." He described this technique as unnoticed by onlookers, and therefore advantageous for adolescents who are concerned about bullying from peers.

Teaching effective wound-care procedures was viewed as very important by all interviewees, particularly when engaging in secretive harm. Donna supported how "you should be able to treat [wounds] so it doesn't get progressively worse”, which is particularly significant as the majority of interviewees felt reluctant to disclose their self-harm to others. Doing Something to Help Yourself. Teaching adolescents alternative ways to harm, as well as providing anatomical information, was seen as equipping them with the ability to choose the extent of harm done to themselves, and to care for themselves properly following self-harm. Cathy suggested how caring for wounds could help others compensate psychologically for self-destructive acts: "A lot of [people] feel guilty afterwards, and they kinda wanna do something to compensate for the fact that they just self-harmed...[wound-caring] might make them feel a bit better about themselves."

Some expressed a shift towards feeling more compassionate towards themselves after learning about harm reduction techniques; Donna, for example, disclosed: “I didn't used to care what I did to myself, sometimes I wouldn't properly dress a wound... I feel like I've got a lot safer now, I care about what I'm doing."

Notably, participants viewed such techniques as a way of protecting friends and family against distressing evidence of self-harm, whilst protecting themselves from the 
stigma of self-harm scars. After using these techniques, Anna commented feeling " a lot better about myself; I've not let anyone down...I haven't hurt myself or other people..."

Utilizing these techniques also helped lessen feelings of regret associated with longterm effects of self-harm. Isaac described his experience of this: "if [cuts] are deep they'll be there for a long time and you'll regret it. But if you punch something like, put a pillow up, it'll hurt but it won't physically damage you."

Less Harm, Same Release. Most participants held positive views about harm reduction as providing alternative methods to damaging self-injurious behaviors. Techniques included eating sour sweets and squeezing ice cubes, although pinging elastic bands was most favored, releasing a sensation similar to extreme harm with reduced harmful effects.

Keith mentioned how harm reduction could avert accidental death in others: "[people] can still get the same kind of sensations that they want but with reducing the risk of harm ... you cut one little bit wrong and there you are, you're gone."

The practicality and accessibility of elastic bands enabled Donna and Beth to release emotional tension discreetly in situations where they would otherwise be unable to self-harm, including public spaces.

Elsa noted that although she still engaged in cutting, learning these techniques allowed her to be mindful of the harm it caused, thereby reducing self-harm frequency. She described this mindful cutting as follows:

“...you can think more about it...say if I did, I don't know, 20 cuts or something, it would be less than that because I'd spend more time trying to not [self-harm]..it's more of an 'actually, you can avoid this'... 'savor this one cut'...."

Theme 2: Barriers to Practising Safer Self-Harm.

This theme describes some barriers to the sustained effectiveness of harm reduction techniques, and the obstacles our participants experienced applying them in everyday life. 
A Double-Edged Sword. Despite the positive aspects of harm reduction strategies discussed, some participants expressed anxieties about providing vulnerable adolescents with anatomical information, possibly encouraging future suicide attempts. Cathy suggested teaching anatomy "may be a bit problematic if the person is suicidal, because they may know exactly where to cut", which was echoed in other narratives.

Harry also suggested teaching wound-care could encourage others to self-harm: "If you're telling [people] how to clean [wounds] it's kinda like if someone killed someone, and you're trying to help them get away with murder ...you're tryna push them towards it...".

Others were concerned about the potential for techniques to fail; Keith worried that even the most seemingly harmless techniques could cause unintentional damage if done incorrectly: “....[a pillow] could be not thick enough and you could snap your wrist or get really damaged wrists. With the ice cube... you hold it too tight and then you put hot water on [yourself], that could cause flash-burning..."

Short-Lived Effects. Whilst harm reduction techniques were viewed as effective by many interviewees, they acknowledged that its effectiveness can be short-lived. For Anna, this related to the reduced level of pain achieved through pinging elastic bands, heightening the risk of self-harm. Similarly, Beth commented that her urges "kept coming back". This creates the potential for magnifying the problem; George recounted how an acquaintance used elastic bands, which led them to crave a more extreme pain sensation: "They were saying it helps but sometimes it ends up leading to wanting to hurting yourself...cos having the sensation of a little bit of pain leads onto wanting more pain'”.

Anna explained that although harm reduction techniques were effective in staving off self-injurious urges for a limited period, it did at least reduce the overall number of episodes: "they helped for the time I was doing it but a few days later I'd self-harm. But it was better than self-harming every day, it slowed down the amount of times I did it...". Whereas Jane 
built up a tolerance to elastic bands, and no longer found it a satisfactory alternative to selfharm.

Despite these perceived drawbacks, participants generally felt that harm reduction provided them with small, manageable goals to support them towards self-harm cessation, which felt more realistic than trying to stop altogether. It was commonly suggested by participants that adolescents who self-harm should learn about harm reduction techniques early on, as a useful preventive tool:

“...if I'd known [harm reduction] earlier on it would definitely be easier to stop, or to try and stop, cos [self-harm] wasn't really something I relied on, whereas further along like, the longer I left it, the harder it was..." (Freya).

A Lack of Motivation. Initiating the transition from invasive self-harm to harm reduction methods was felt to be a potential challenge for youths who might strongly desire the pain self-harm elicits. Harry explained: “...it's just the motivation ...trying to get yourself over that mind[set] of knowing you're not gonna hurt, like you're gonna punch something but you know it's not gonna hurt...". Others commented on how the emotional toll exerted by selfharming can demotivate them to clean wounds or equipment: "I don't always want to... I just feel so low, like I just don't wanna do anything...." (Cathy).

Some interviewees felt the usefulness of harm reduction depended on a person's state of mind. Freya highlighted how the effects "depend on how long you've been [self-harming]; how bad it's got...how you are in your head."

Notably, some anticipated that other adolescents might lack motivation to try novel harm reduction techniques. Anna suggested this might be "cos they think they aren't going to work or get the same output.". Elsa viewed professional help as a way of overcoming this barrier: 
“When you want to [self-harm] you aren't very likely to be like "oh, I'm going to go try this" cos it might not work. Then what's the point, you've wasted your time...giving [young people] the opportunity to try it [with a practitioner], I think that's probably a good idea..."

The Strong Influence of Impulsivity. Interviewees reported an inability to apply harm reduction techniques in the heat of the moment due to strong self-injurious urges. Anna explained: "I'd [self-harm] either when I was very angry or really depressed, and [reducing harm] is not what I was thinking about". Both Elsa and Jane recalled times when the urgent need for a release had stopped them from cleaning equipment or paying attention to anatomy, whereas Cathy related this to the wider population: "In the moment [people] wanna cause as much harm as possible...[they] don't actually wanna permanently injure themselves or kill themselves...but [they] don't think about the after effects."

Theme 3: Developing a Broad Repertoire of Harm Reduction Techniques.

Each participant spontaneously described distraction-based techniques, related to information learnt from MAB or other sources, as ways to reduce self-injurious urges. These included listening to music, watching horror films, and exercise. Some participants favored safety behaviors, such as taking themselves somewhere where they were unable to self-harm until the urge passed. For one participant, distraction-based mobile apps helped Cathy ground her urges as they provided personalized alternative suggestions to self-harm behaviours. Drawing on the skin was another preferred technique; helping George feel 'as if [a cut] was there but it wasn 't', and supported others in satisfying their need for visualizing physical damage. Interestingly, Anna chose to personalize this strategy to elicit an emotional response, preventing her from causing serious damage:

"II] drew a butterfly on my wrist so if I cut it, I'm killing the butterfly...no one would draw a picture of an animal on yourself and then harm it...or even [writing] a name...someone close to you, cos they mean a lot to you." 
Furthermore, Isaac suggested how others could combine different techniques to gain more of an effect in satisfying their self-harm urges: "Some people might wanna see blood, they can always just draw with a red pen and ping an elastic band." Similarly, Keith described how he adapted harm reduction techniques to suit his needs, choosing to carve into cardboard or wood rather than cutting himself.

Cathy also commented on the necessity of therapeutic support alongside harm reduction techniques to address underlying reasons for self-harm: "harm reductions reduce the intensity of self-harm, but it doesn't really get rid of the urge... what [adolescents] should do is use them as place-holders cos the main issue here is how the person thinks...".

\section{Discussion}

\section{Main Findings}

Our three themes identify mixed views regarding the usefulness of harm reduction techniques for self-harm. Participants discussed the importance of harm reduction approaches empowering them to help themselves; decreasing their sense of regret and compensating for extreme injurious self-harm by being able to follow wound-care protocols. Providing youths with independence and freedom of choice through the provision of anatomical knowledge and effective wound-care was seen as giving them greater competence in managing their selfharm. However, participants expressed concerns about the short-lived utility and potential negative consequences of harm reduction, including providing high-risk individuals with necessary information to cause further harm or attempt suicide.

The limitations identified by participants included an inability to apply techniques in the heat of the moment, for example, in situations where they sought extreme selfpunishment or became overwhelmed by impulsive urges. Notably, where interviewees referred to harm reduction as futile, this was in relation to a perceived lack of motivation in others, rather than personal experiences. 
Our findings also suggest that harm reduction practises are perhaps more diverse than previously described in the literature. Our data yielded a rich set of examples of personalized distraction-based techniques and safety planning approaches that participants had developed as helpful tools in warding off self-injurious urges. Many of these we had not encountered previously in the published literature nor in our clinical work with people who self-harm, including carving into wood, and techniques commended by The Butterfly Project, such as drawing butterflies or writing the names of friends or relatives on the skin (Adolescent Self Injury Foundation, 2020). The wide range of creative approaches described, falling outside the usual harm reduction paradigm but clearly derived from it, suggested that when adolescents are educated in harm reduction principles they are empowered to develop techniques to suit their preferred method of self-harm, along with their hobbies and interests.

\section{Findings in the Context of Other Studies}

Our findings were broadly consistent with the few previous studies attempting to explore the effectiveness of harm reduction in managing adolescent self-harm. Livesey (2009)'s retrospective analysis of adolescent in-patient experiences found the introduction of a harm reduction policy was viewed positively by practitioners as meeting a need for flexible responses towards self-harm behaviors. Our findings echoed this, as many adolescents held positive opinions of harm reduction, as well as safety planning and distraction-based techniques.

Some participants found harm reduction useful depending on their emotional state and how long they had been self-harming, similar to the findings of another British qualitative study by Wadman et al. (2019). However, data from some participants in Wadman's study described this approach as ineffective, whilst only a small proportion of our participants expressed such views. It is possible that these different perspectives reflect the views of different populations, given that we interviewed service users from a harm reduction 
program, whilst Wadman's analysis was of secondary data from community and clinical samples, not specifically collected to probe views on harm reduction.

Although the short-lived effects of harm reduction techniques are both expected and reasonable (NICE, 2011), participants voiced concerns over it leading to an increase in tolerance and sensation-seeking. These concerns parallel those of mental health professionals (James et al., 2017), implicating careful application and monitoring of such techniques.

Similarly, participants' concerns over misuse of anatomical information were consistent with an associated study in this research program, interviewing parents of young MAB clients and practitioners (Bamber et al., in preparation), highlighting parental concerns about the potential for anatomical information to promote extreme self-harm or death. Similar professional concerns have been reported by Sullivan $(2017 ; 2019)$, and James et al. (2017), emphasizing the need for caution when teaching this particular strategy to high-risk populations.

\section{Strengths and Limitations}

We used a purposive sampling methodology to recruit adolescents from a help-seeking population, reflecting a range of experiences. A balanced sample, inclusive of both male and female views, reflected the distribution of self-harm.

Whilst JD's lived experiences of self-harm assisted her in gaining a clearer understanding of interviewees' perspectives, this potentially introduced inductive bias (Smith \& Noble, 2014). However, this was in keeping with the study's interpretivist stance, and was balanced by a collaborative team approach to data coding and interpretation. This approach also helped mitigate potential analysis bias, strengthening the study's ecological validity.

This study is the first to collect data specifically investigating the usefulness of harm reduction techniques in managing self-harm amongst those who self-harm. Other recent research relied on secondary analyses of data not specifically collected to explore views on 
harm reduction (Wadman et al., 2019). Our study therefore presents valuable perspectives of young service users who engage in self-harm with implications for supporting self-harm recovery.

However, our results should be considered in light of several limitations. We recruited from a defined help-seeking population, introducing potential response biases; as MAB operate from a harm reduction framework, clients may be more well-disposed towards harm reduction than others, due to active engagement and practitioner support. Similarly, service users who actively engage in such strategies may have been more likely to volunteer for interview. Our participants may therefore be regarded as highly experienced and competent in utilizing such techniques, and our results may not be generalizable to all adolescents who self-harm.

Whilst data saturation was achieved after 11 interviews, a wider range of ages and ethnic diversities may have provided our sample with a greater variation of experiences. Recall bias may have impacted the validity of participant accounts, as those with a history of self-harm had difficulty recalling past experiences.

\section{Clinical and Research Implications}

Participants' reservations about harm reduction techniques related to the potential risks of providing anatomical information to vulnerable adolescents, implying that aspects of harm reduction relating to anatomical teaching need further careful evaluation. Meanwhile, primary and secondary care services may feel comfortable implementing education in other harm reduction practices, such as wound-care, provided that appropriate risk assessments and monitoring practices are arranged.

Participants perceived hesitancy in their peers to try harm reduction techniques due to preconceptions about their ineffectiveness. To address this barrier, those working in mental health services may need training to teach these techniques, such as providing adolescents 
with a safe space to trial them in the presence of practitioners. Given the potential for these practical approaches to draw the focus away from underlying psychological precursors, it is important for such interventions to be offered in conjunction with therapeutic support (Hawton et al., 2015b). Schools might also consider raising awareness of such approaches, perhaps avoiding the more contentious issue of providing anatomical information. This may increase accessibility of techniques for adolescents who self-harm and those at future risk.

Future research calls for similar qualitative studies to explore the acceptability of harm reduction techniques amongst adolescents, parents, teachers, and mental health practitioners in a range of settings (e.g., inpatient vs outpatient), including among ethnic minority groups and adolescents unknown to mental health services. Considering the lack of research on this topic, this will provide a comprehensive exploration of the potential contribution the harm reduction paradigm may bring in reducing risks associated with selfharm.

Our participants viewed harm reduction techniques as a way of exercising their independence, whilst protecting friends and family against distressing aspects of self-harm. Although this presents harm reduction in a positive light, it may make adolescents less likely to seek help, and further research may be beneficial to determine the likelihood of such risks.

Finally, our findings described a broad repertoire of harm reduction techniques applicable to a wide variety of self-harm behaviours, suggesting we need to broaden clinical definitions of harm reduction, and encourage adolescents who self-harm to develop creative and individualized techniques. Formal randomized controlled trials of such are essential to investigate their clinical effectiveness in the repertoire of interventions for self-harm.

\section{Conclusion}

Our findings present a range of views regarding the acceptability of the harm reduction paradigm and suggest a broad repertoire of techniques for managing self-harm. Most 
adolescents described positive experiences, albeit acknowledging short-lived effects in some cases. Our study suggests wider access to education in harm reduction may be beneficial, not necessarily including anatomical information considering the potential for vulnerable adolescents to misuse this. Our work also suggests that coping techniques including distraction activities should be considered as part of the repertoire of harm reduction and offered alongside psychological therapy to provide comprehensive support. 


\section{Acknowledgements}

We would like to thank Mind and Body for their assistance in recruitment and providing interview rooms in youth hubs, and all the secondary schools throughout Kent that consented to participate and provide interview rooms. We would also like to thank the 12 interviewees, as well as all parents/guardians who consented to their child's participation.

\section{Declaration of Interest}

All authors declare no conflict of interests. Mind and Body helped in the recruitment of participants but had no influence over the data provided within the interviews; the design and conduct of the study; collection, analysis, and interpretation of the data, or the writing of the final manuscript. The views expressed are those of the authors and not necessarily those of MAB.

\section{Funding}

JB, AP, and SR are supported by the NIHR University College London Hospitals Biomedical Research Centre (NIHR UCLH BRC). This work was funded by a UCL Division of Psychiatry MSc fund to JD. 


\section{References}

Adolescent Self Injury Foundation. (2020). The butterfly project. Retrieved July 18, 2020, from https://www.adolescentselfinjuryfoundation.com/the-butterfly-project

Aliyu, A. A., Singhry, I. M., Adamu, H. I., \& Abubakar, M. M. (2015). Ontology, epistemology and axiology in quantitative and qualitative research. Proceedings of The Academic Conference: Mediterranean Publications \& Research International on New Direction and Uncommon. 2(1). Abekuta, Ogun State, Nigeria: University of Agric.

Bamber, V., Morant, N., Davies, J., Pitman, A. L., \& Rowe, S. (In prep). Parents' ${ }^{\text {and }}$ carers' perspectives on the role of harm reduction techniques in managing self-harming behaviours in young people: a qualitative study.

Birch, S., Cole, S., Hunt, K., Edwards, B., \& Reaney, E. (2011). Self-harm and the positive risk taking approach. Can being able to think about the possibility of harm reduce the frequency of actual harm? Journal of Mental Health, 20(3), 293-303. doi:10.3109/09638237.2011.570809

Borschmann, R., Becker, D., Coffey, C., Spry, E., Moreno-Betancur, M., Moran, P., \& Patton, G. C. (2017). 20-year outcomes in adolescents who self-harm: a populationbased cohort study. The Lancet Child \& Adolescent Health, 1(3), 195-202. doi:10.1016/S2352-4642(17)30007-X

Braun, V., \& Clarke, V. (2006). Using thematic analysis in psychology. Qualitative Research in Psychology, 3(2), 77-101. doi:10.1191/1478088706qp063oa

Cully, G., Corcoran, P., Leahy, D., Griffin, E., Dillon, C., Cassidy, E., ... \& Arensman, E. (2019). Method of self-harm and risk of self-harm repetition: findings from a national self-harm registry. Journal of Affective Disorders, 246, 843-850. doi:10.1016/j.jad.2018.10.372 
Doyle, L., Treacy, M. P., \& Sheridan, A. (2015). Self-harm in young people: Prevalence, associated factors, and help-seeking in school-going adolescents. International Journal of Mental Health Nursing, 24(6), 485-494. doi:10.1111/inm.12144

Gonzales, A. H., \& Bergstrom, L. (2013). Adolescent non-suicidal self-injury (NSSI) interventions. Journal of Child and Adolescent Psychiatric Nursing, 26(2), 124-130. doi:10.111/jcap.12035

Gurung, K. (2018). Bodywork: Self-harm, trauma, and embodied expressions of pain. Arts and Humanities in Higher Education, 17(1), 32-47. doi:10.1177/1474022216684634

Hawton, K., Bergen, H., Cooper, J., Turnbull, P., Waters, K., Ness, J., \& Kapur, N. (2015a). Suicide following self-harm: findings from the Multicentre Study of self-harm in England, 2000-2012. Journal of Affective Disorders, 175, 147-151. doi:10.1016/j.jad.2014.12.062

Hawton, K., Harriss, L., \& Zahl, D. (2006). Deaths from all causes in a long-term follow-up study of 11583 deliberate self-harm patients. Psychological Medicine, 36(3), 397-405. doi:10.1017/S0033291705006914

Hawton, K., Saunders, K. E., \& O'Connor, R. C. (2012). Self-harm and suicide in adolescents. The Lancet, 379(9834), 2373-2382. doi:10.1016/S0140-6736(12)60322-5

Hawton, K., Witt, K. G., Salisbury, T. L. T., Arensman, E., Gunnell, D., Townsend, E., ... \& Hazell, P. (2015b). Interventions for self-harm in children and adolescents. Cochrane database of Systematic Reviews, (12). doi:10.1002/14651858.CD012013

Holley, C., Horton, R., Cartmail, L., \& Bradley, E. (2012). Self-injury and harm minimisation on acute wards. Nursing Standard, 26(38), 51-56. doi:10.7748/ns2012.05.26.38.51.c9113

Hosie, L., \& Dickens, G. L. (2018). Harm-reduction approaches for self-cutting in inpatient mental health settings: Development and preliminary validation of the Attitudes to 
Self-cutting Management (ASc-Me) Scale. Journal of Psychiatric and Mental Health Nursing, 25(9-10), 531-545. doi:10.111/jpm.12498

Inckle, K. (2011). The first cut is the deepest: A harm-reduction approach to selfinjury. Social Work in Mental Health, 9(5), 364-378. doi:10.1080/15332985.2011.575726

James, K., Samuels, I., Moran, P., \& Stewart, D. (2017). Harm reduction as a strategy for supporting people who self-harm on mental health wards: The views and experiences of practitioners. Journal of Affective Disorders, 214, 67-73. doi:10.1016/j.jad.2017.03.002

Kelly, C. M., Jorm, A. F., Kitchener, B. A., \& Langlands, R. L. (2008). Development of mental health first aid guidelines for deliberate non-suicidal self-injury: a Delphi study. BioMed Central Psychiatry, 8(1), 62-72. doi:10.1186/1471-244X-8-62

Livesey, A. E. (2009). Self-harm in adolescent in-patients. Psychiatric Bulletin, 33(1), 10-12. doi:10.1192/pb.bp.107.016022

Madge, N., Hawton, K., McMahon, E. M., Corcoran, P., De Leo, D., De Wilde, E. J., ... \& Arensman, E. (2011). Psychological characteristics, stressful life events and deliberate self-harm: findings from the Child \& Adolescent Self-harm in Europe (CASE) Study. European Child \& Adolescent Psychiatry, 20(10), 499-509. doi:10.1007/s00787-011-0210-4

National Institute of Health and Care Excellence (2011). Longer-term treatment and management of self-harm. Retrieved from: https://www.nice.org.uk/guidance/CG133/chapter/1-Guidance\#longer-term-treatmentand-management-of-self-harm

Owens, C., Hansford, L., Sharkey, S., \& Ford, T. (2016). Needs and fears of young people presenting at accident and emergency department following an act of self-harm: 
secondary analysis of qualitative data. The British Journal of Psychiatry, 208(3), 286291. doi:10.1192/bjp.bp.113.141242

Pengelly, N., Ford, B., Blenkiron, P., \& Reilly, S. (2008). Harm minimisation after repeated self-harm: Development of a trust handbook. Psychiatric Bulletin, 32(2), 60-63. doi:10.1192/pb.bp.106.012070

Peters, C., Bruun, A., Moncrieff, J., Pitman, A., Morant, N., Rowe, S. (In prep). The role of harm-minimisation in self-harm management: a thematic analysis of personal blog posts. Manuscript in preparation.

Polit, D. F., \& Beck, C. T. (2006). The content validity index: Are you sure you know what's being reported? critique and recommendations. Research in Nursing \& Health, 29(5), 489-497. doi:10.1002/nur.20147

Smith, J., \& Noble, H. (2014). Bias in research. Evidence-based Nursing, 17(4), 100-101. doi:10.1136/eb-2014-101946

Sullivan, P. J. (2017). Should healthcare professionals sometimes allow harm? The case of self-injury. Journal of Medical Ethics, 43(5), 319-323. doi:10.1136/medethics-2015103146

Sullivan, P. J. (2019). Risk and responding to self injury: is harm minimisation a step too far?. The Journal of Mental Health Training, Education and Practice, 14(1), 1-11. doi:10.1108/JMHTEP-05-2018-0031

Townsend, E. (2014). Self-harm in young people. Evidence-based Mental Health, 17(4), 9799. doi:10.1136/eb-2014-101840

Wadman, R., Nielsen, E., O’Raw, L., Brown, K., Williams, A. J., Sayal, K., \& Townsend, E. (2019). “These Things Don’t Work.” Young People’s Views on Harm Minimization Strategies as a Proxy for Self-Harm: A Mixed Methods Approach. Archives of Suicide Research, 1-18. doi:10.1080/13811118.2019.1624669 


\section{Topic Guide for Young Person}

Young peoples' perspectives on the role of harm reduction techniques in the management of their self-harm: A qualitative study

Introduction:

\section{Opening}

- [Establish Rapport] Hi, my name is [researcher name]. Thank you for taking the time to let me interview you today. How are you today?

- [Purpose] So, today I'd like to ask you some questions about your experiences of self-harm. The study is particularly interested in harm reduction strategies that you may or may not use.

- I've been studying self-harm for a number of years, and I'm aware of a lot of reasons why people self-harm, and I know that a lot of people talk about needing to prevent self-harm thoughts, however, this interview is based around your thoughts on the effects of harm reduction techniques.

- We are conducting this study to improve our understanding of the effectiveness of harm reduction, and to gain insight from a young person's point of view. This interview is based on your views, there are no right or wrong answers, and I will not judge anything you say here today.

\section{Outline of respondents' rights:}

- [Freedom to decline to answer/withdraw] So, before we start, I'd like to outline some important things. As this is a sensitive topic, you have the choice to not answer any question that makes you feel uncomfortable. If at any point you want to take a break, or to stop the interview, please let me know. You can also take as long as you'd like to answer any question I ask. If you decide that you don't want your interview analysed, we will delete all answers collected. Please be aware that if you do choose to end the interview, the service you receive from the Mind and Body programme will not be affected in any way.

- [Confidentiality] This is a safe space and anything you share with me today will not be judged and will be kept confidential. However, if you do say anything that makes me concerned about your safety or the safety of others, I will have to let your practitioner at Mind and Body know about it. But if this does happen, I will let you know during our talk today. I have an audio recorder here to record our conversation, and this will be transcribed by me or an external transcribing service if you have agreed to this on your consent form at a later date, unless you wish to withdraw your data, which you can do at any time until $15^{\text {th }}$ August, 2019. But if you feel like you may want to withdraw your data soon after the interview, would you mind letting me know by [insert closer date], I'd be really grateful for that as I'd be able to prioritise transcribing other interviews instead.

- $\quad$ [Timing] This interview should take no longer than an hour. But is it quite flexible, and it will depend on how much you have to say for each question.

- [Questions] Do you have any questions before we begin? Would you like to have a drink?

General Questions

\section{$\underline{\text { Body }}$}

[Transition into this topic] $\rightarrow$ I'm going to start off by asking some general questions about you.

1) How old are you?

2) What gender do you identify as?

3) How do you define your ethnic group? 
4) Approximately, how long have you been going to Mind and Body?

a. How often do you attend?

b. How are you finding the programme?

\section{Experiences of self-harm}

[Transition into this topic] $\rightarrow$ Okay, thank you. Now, I'd like to ask you about your experiences of self-harm. As self-harm is quite subjective, in that people have different definitions of what self-harm means to them, could you tell me what you think of when you hear the words 'self-harm'?

Remember, there are no right or wrong answers.

\section{\{wait for a response\}}

Okay that's great, so please know that from now on, when I say the words 'self-harm', that is the sort of behaviour I am referring to, so that its more personal to you.

1) Can I get your views on the function of self-harm?

2) When did you start self-harming?

a. Could you tell me a little bit about why you started?

3) Could you tell me how often you self-harm if you still do?

4) Could you tell me what methods you tend to use?

5) Could you describe any known triggers for those behaviours?

6) Could you describe to me how harming yourself makes you feel?

7) When you first started feeling urges to harm yourself, did you seek any help/tell anyone?

a. [If yes] From whom/what services?

b. [If no] Why not?

8) I understand these questions may not be easy to answer, are you okay to continue?

\section{Harm-reduction}

[Transition into this topic] $\rightarrow$ Thank you. Now I'm going to ask you about your experiences of harm-reduction techniques... and when I talk about harm reduction I mean interventions that acknowledge that you self-harm as a way to cope, so rather than telling you to stop self-harming all together, they aim to reduce the physical damage caused. This may include teaching you about proper wound-care and how to spot/stop infections, learning about the anatomy, sterilising equipment you may use, and teaching alternative harming techniques such as pinging an elastic band on your skin, squeezing ice cubes, or punching a wall covered by a pillow to cope with distress rather than hurting yourself in a more extreme way. So, you continue to harm, but these techniques help to lessen the damage done.

1) Are you familiar with harm reduction techniques?

a. [If yes] Where did you learn about these techniques?

b. [If no] Were there any techniques that you have heard about before this interview?

2) What are your views of these?

a. What do you think about techniques such as learning to properly clean wounds and stopping infections being taught to others?

b. Do you think that these interventions that recognise the function of self-harm are accepted by professionals?

c. Can you summarise the effectiveness of these techniques in your own opinion?

3) Can you think of any harm reduction strategies that you have tried in the past?

a. [If yes] Could you give me some examples of some you've used?

i. Out of these, can you describe any you felt were particularly useful/any you like to do?

ii. [If yes] Can you think of any reasons why this/these were useful for you?

iii. How do you feel after you use a harm-reduction strategy?

iv. Can you tell me if there are any that made your feelings worse? 
v. [If yes] Can you think of any reasons why this/these weren't useful for you?

vi. Can you tell me any that you don't use?

b. [If not] Would you like some more examples to help with this question?

4) Are there any that you may want to use in the future?

a. [If yes] Can you give me any examples that come to mind?

i. What is it about this/these technique(s) that makes you want to give it/them a try?

b. [If no] Can you tell me why you may not want to give them a try?

5) If a friend of yours were to try some of these techniques, how do you think you'd feel about this?

a. [If yes] Why?

i. Are there any techniques in particular that you would suggest to them?

b. [If no] Why not?

6) Since becoming aware of harm reduction techniques, have you noticed any changes in the way you self-harm?

a. [prompt] Do you self-harm more or less or the same amount for example?

b. Could you tell me more about this?

7) Do your parents know that you use harm-reduction techniques?

a. [If yes] What are their views on this?

b. [If no] Is this something you'd be comfortable sharing with them?

8) In your opinion, are there any negatives about such harm-reduction techniques?

a. Teaching information such as anatomy, where is safer/dangerous to cut is quite controversial, can you give me your view on this?

9) In your opinion, are there any positives about such harm-reduction?

10) At the moment, harm reduction strategies are not widely used in the community, in fact they are still discouraged, can you think of any reason why this may be the case?

a. [Provide prompt if needed] - so, in other outpatient programmes, or communitybased groups for other people who also self-harm or have depression

11) Harm reduction techniques are criticised by some practitioners, and some interventions shy away from it, as it can be seen as encouraging a less harmful form of self-harm rather than discouraging it completely, can you tell me your views on this?

a. Which way do you feel is the best approach for someone who is struggling with selfharm (harm reduction or prevention)?

12) What do you think of harm reduction techniques being taught within other community services to help other young people?

a. [If they answer positively or negatively] Why do you think this?

b. [If they don't know/aren't sure - potentially rephrase the question] In an ideal world, would harm reduction techniques be used in other community services?

13) Can you think of any way that the teaching of harm-reduction techniques could be improved?

14) Do you think the teaching of harm reduction may reduce or increase stigma around selfharm?

15) Do you think the teaching and acceptability of harm-reduction techniques may affect help seeking behaviours in young people who are struggling, if at all?

\section{Closing}

[Summarise] Ok, so that's the end of the interview. We've talked a lot about your experiences of self-harm, and how harm reduction strategies work or may not work for you. [briefly summarise the key points discussed by YP].

[Maintain rapport] I understand this may be an uneasy topic for you, so I really appreciate your participation. 
1. I was wondering if you had anything else you'd like to add that you think may be helpful for our research that we didn't cover during the interview?

2. Do you have any questions you'd like to ask before we finish?

[Following action] Thank you for taking part, your answers have been really helpful.

If you have any further questions after the interview, please contact myself or my supervisor, our contact details are on the information sheet. Also, if you choose to withdraw from the study at any time up until the $15^{\text {th }}$ August 2019, please don't hesitate to contact myself or my supervisor.

If not, our next steps will be to transcribe this interview and others using different names so that you or anyone you mentioned won't be identifiable. And please if you feel any distress at all after this interview, let your practitioner at Mind and Body know.

So now, the answers from each interview will be analysed to identify any common themes, and it will be written up in a report. If you have chosen to receive a copy of the final report on your consent form, you will hear from us in September.

[Give participant the voucher]

Thank you once again for taking part, have a good day. 